\title{
Cuzco o la Metáfora como Patrimonio
}

\section{Henrique Urbano}

\section{EI problema: un puma del siglo XIX}

Un estudio de Barnes y Slive' plantea en forma clara un problema que sirve de tela de fondo a mis disquisiciones en torno a la construcción metafórica de la ciudad de Cuzco y por ende, al concepto de ciudad en términos de espacio físico y mental en tiempos precolombinos. La cronistica de los siglos XVI y XVII y, en nuestros días, el ejército de arqueólogos, antropólogos y exploradores que pasaron por la ciudad de Cuzco asumieron como testimonios vivos y verdaderos, las anécdotas que hablaban de un diseño arquitectónico de la ciudad que reproducia la figura de puma por expresa voluntad del inca Pachacutec, después de su victoria frente a los chancas. Para sustentar su opinión refieren los estudiosos la existencia de los relatos que circulaban sobre ese hecho y la propia figura física del espacio en que, según cuentan, se ve el diseño del puma. Y para dar más fuerza al argumento recordaban que existía en una parte de la ciudad, a la que llamaban Hurin Cuzco, un lugar llamado Pumachupan Cola del Puma - que sugeriría la real acción de Pachacutec Inca en la refundación de la ciudad, siendo ese lugar el que correspondería a la cola de dicho animal.
La ciudad del Cuzco posee en su vertiente Oeste unas construciones que conforman lo que los españoles llamaron "Fortaleza". Ubicadas en una de las partes más altas del espacio del valle contrastan con la parte anteriormente referida, Pumachupan. Por consiguiente, las descripciones que hacen referencia a la figura de puma recurren a esas construcciones para designarlas como "cabeza". Y naturalmente el cuerpo de la ciudad se confundiría con el cuerpo del puma a través de sus edificios donde destacarian el Templo del Sol, la plaza Huacaypata y algunos otros galpones de buena hechura y fina cantería.

En su expresión más descarnada los datos que acabo de mencionar son los que siven de argumento para declarar aceptable la idea de la existencia de la ciudad en forma de puma. Squier y los arqueólogos contemporáneos Rowe y Chávez Ballón defienden esa opinión. No hay otros argumentos. Rowe comenta que esa idea le vino a Chávez Ballón, quien, según él, probaba fehacientemente con muros y edificios la existencia del "cuerpo del puma". Y como si ya no fuera poco semejante dislate añade el siguiente comentario: "It is one of many important and original contributions which Professor Chávez has made to our understanding of the Inca capital" (Rowe 1967: 65 n.9). 
Ahora bien, lo que parece razonable en términos de diseño proyectado en el espacio de Cuzco no lo es tanto cuando se someten a un riguroso estudio los relatos que conforman el discurso sobre la fundación de la ciudad y de la figura de puma como proyecto espacial ${ }^{2}$. $Y$ es esa duda metodológica que me servirá de pretexto para cuestionar el discurso sobre el diseño del espacio urbano de Cuzco y, al mismo tiempo, encontrar una respuesta a la existencia del relato mítico que justifica el gesto fundacional del inca Pachacutec. Resumo. Existen tres entradas para la duda que yo planteo: primera duda, el inca Pachacutec refunda la ciudad imitando la figura de un puma; segunda duda, los cronistas españoles o indígenas reproducen el relato o reconstruyen el diseño según los valores y normas que les ofrece la cultura peninsular del siglo XVI y XVII; tercera duda: el discurso sobre el espacio de la ciudad del Cuzco es una invención de la cronística española en base a ciertos elementos etnográficos del siglo XVI.

Una simple lectura de los textos que recogieron el relato mítico y atribuyeron a Pachacutec el diseño del puma da muestras evidentes de tratarse de una metáfora. $Y$ los elementos estilísticos que le sirven de herramienta confirman esa lectura. Así lo sugirió, hacia varios años, Zuidema con su acostumbrada prosa desordenada e incomprensible. No obstante, de ese magma se pudo vislumbrar una crítica a la aceptación boba de los datos vertidos en la cronistica del siglo XVI y XVII por parte de los arqueólogos Rowe y Chávez Ballón. Barnes y Slide trajeron a colación los argumentos pertinentes y zahondaron la intuición de Zuidema (1983), dándole sustento y lógica. Aporte sustancial. Desde ese entonces, conocemos con abundantes y sustanciosas pruebas la existencia de un discurso hispánico sobre el espacio donde el puma - o su versión europea, el león desempeña un papel protagónico. Recordemos algunos argumentos.

\section{La metáfora del puma en el discurso de los siglos XVI y XVII sobre el espacio urbano cuzqueño.}

\author{
El texto de Betanzos (1551).
}

"(...) y a toda la ciudad junta nombro cuerpo de león diciendo que los tales vecinos e moradores del eran miembros del tal león y que su persona era la cabeza del (...)" (Betanzos 1987: 65). En ese mismo capítulo menciona el cronista el hecho siguente: "...el cual les estaba pintando y dibujando ciertas puentes y la manera que habian de tener e como habian de ser edificadas $e$ ansi mesmo dibujaba ciertos caminos que de un pueblo salían..."

En otras palabras, el inca se encargaba de diseñar no sólo la traza de la ciudad sino también el espacio en general. $Y$ sin mayores precisiones.

Esa idea de que el inca diseña el espacio y ubica en él las cosas y los hombres con sus diferencias regionales y en general, culturales, tiene profundas raices en la tradición andina. Se cuenta del héroe Wiracocha que " (...) hizo de piedra cierto número de gente y un principal que la gobernaba (...)" (Betanzos 1987 [1551]: 11). Y no es la única referencia a esa forma de ordenar el espacio. Por lo que, concluyo yo, los hombres, las sociedades y las cosas deben su existencia y forma de ser al gesto de un héroe que los concibió en forma de dibujo y a partir de ahi los ubicó en el mundo, llamándolos a la existencia en el lugar donde ahora existen ${ }^{3}$.

Dos planes se confunden en esta perspectiva de Betanzos: primero, el gesto del héroe Wiracocha en el ciclo mítico del origen del mundo y de las cosas; segundo, el gesto del Inca Pachacutec en el diseño de la ciudad de Cuzco. Misma intención, mismo gesto. La lógica del discurso mítico andino sobre los orígenes lo exigía. Nótese, sin embargo, que la "cabeza del 2 El estudio de Barnes y Slive mencionado anteriormente contiene las referen-
cias a todos los lexlos conocidos sobre el tema. Para no repetir los textos y los
argumentos, el lector podrá consultar ese notable y exhaustivo articulo. 
puma" es el propio Pachacutec Inca mientras que, en el ciclo mítico de Wiracocha, no hay "cabeza" sino héroes que presidirán al desarrollo de los pueblos y cosas.

Texto de Sarmiento de Gamboa (1572). Mucho más explícito que Betanzos, el cronista casi oficial de Francisco de Toledo cuenta lo siguiente:

"Después que Topa Inga Yupangui visitó la tierra toda y se vino al Cuzco, donde era servido y adorado, como se vido ocioso, acordóse que su padre Pachacuti habia llamado a la ciudad del Cuzco la ciudad león, y que la cola era adonde se juntan los dos rios que pasan por la ciudad, y que dijo que el cuerpo era la plaza y las poblaciones de la redonda, y que la cabeza le faltaba, mas que algún hijo suyo se la pondría. Y asi, consultado este negocio con los orejones, dijo que la mejor cabeza que le podría poner sería hacerle una fortaleza en un padrasto alto que la ciudad tiene a la parte norte" (Sarmiento de Gamboa 1960 [1572]: 257-258).

Sarmiento de Gamboa emplea formas estilísticas que dan mayor verosimilitud a la construcción de la imagen de la ciudad en forma de puma, aunque la expresión literaria empleada ignora la tradición oral manifiesta que, según vimos, otorga al inca el acto de diseño de la obra. $Y$ ahi precisamente reside la gran diferencia entre el texto de Sarmiento y el de Betanzos. Mientras el primero se atiene a la construcción histórica del incario basada en los relatos de las averiguaciones hechas por cuenta de Francisco de Toledo, el segundo desarrolla en un estilo tosco y desaliñado la palabra de los narradores de historias. Este es solidario con la palabra de los viejos testimonios de la ciudad, aquel de los escritores contratados por los administradores de la Corona española. Sarmiento era menos sensible a la oralidad prehispánica; Betanzos, refugiado en el Cuzco, pretendía dar a conocer lo que sus oídos escucharon acerca de las historias de los incas. Era Sarmiento letrado esotérico, Betanzos, añoso contador de historias.

\section{Puma chupa o Cola del Puma entre los barrios incaicos del Cuzco}

Entre las referencias de la cronística de los siglos XVI y XVII, existen algunas a un lugar en la ciudad del Cuzco que se llama Pumachupan o Cola del Puma. No me extrañaría que sea el nombre de esta zona el culpable de la confusión en torno al nombre de Cuzco-Puma. Una de las historietas referidas por Cobo (1652) cuenta que la coya, esposa de Capac Yupangui, era muy hermosa y organizaba grandes fiestas en la Plaza del Cuzco a la cual mandaba traer gran variedad de animales feroces. Cuando murió su esposo, la tristeza la sumergió en pesadas noches de llanto y desconsuelo. Y para borrar la memoria de alegrías pasadas mandó sacar de la Plaza arboledas y plantas, reponiéndolas en el barrio de Pumachupan (Cobo, II 1964 [1652] 1964: 72). No es la única referencia a este barrio. Cobo y otros cronistas lo mencionan en un acto ritual durante las fiestas de Capac Raymi allá por diciembre/enero: hacian un sacrificio de un animal, molían los huesos y el polvo que no se levantaba lo guardaban en un buhío de Pumachupan (Cobo, II, 1964 [1652]: 209; Molina, El Cuzqueño 1989 [c.1574]: 115). También se menciona Pumachupan para señalar el encuentro de los dos ríos - el Saphi y el Tullumayo - en el fondo de la ciudad, que, como es sabido, desempeñaba un papel importante en la simbólica ritual incaica. Esos encuentros de la naturaleza se llamaban tinkuy (Cobo, II, 1964[1653]: 213). En una de las descripciones de los adoratorios de la ciudad, Cobo escribe:

(...) Pomachupa (suena cola de león). Era un llano que estaba en el barrio así llamado, y desde allí se ofrecía a aquellos dos riachuelos que por allí corren (Cobo II , 1964[1653]: 183).

Todos estos datos se refieren al espacio llamado Hurin Cuzco o Cuzco Bajo. Según la metáfora de Garcilaso de la Vega, Hurin Cuzco era la mitad que correspondía a la coya, mientras la parte de arriba -Hanan-, al inca (Garcilaso, I, 1943 [1609]: 43). La mitad Hurin expresaba el rango social de los que ahí moraban, por lo tanto, inferior al de los habitantes de Hanan y del inca. La referencia al diseño de la 
figura de puma para definir la ciudad no se menciona en Garcilaso, pero refiere que existían feroces leones allá por Pumachupan, razón del nombre del barrio.

\section{Cuzco: el discurso iconográfico de Guamán Poma (¿1613?) o la metáfora olvidada.}

La crónica que se conoce con el nombre de Nueva Crónica y Buen Gobierno lleva como autor a Phelipe Guaman Poma de Ayala. Guaman Poma conocía las regiones del surandino donde ayudó a "extirpar idolatrías" y a implementar algunos negocios familiares. Su nombre llevaba la palabra puma. Notable es su texto en lo que atañe a diseños de ciudades (Husson 1984). Un gran número de ellas abarcan el Continente. El autor posee un extraordinario sentido del imaginario urbano y emplea el dibujo como forma casi instintiva de explicarlo. No me alargaré en explicaciones sobre todos sus dibujos. Me concentraré en el diseño de la ciudad de Cuzco (Ver Diseño-1).

Para dar más relieve a las figuras, dividí en tres campos los espacios que separan los tres renglones de diseños. En el espacio del centro prevalecen las plazas: Haucaypata, Cusipata con sus vendedores y Cusicancha. $Y$ el diseño inferior: Pumachupan. En los dos renglones de figuras que acompañan las imágenes centrales vienen del lado izquierdo las que se refieren a la Fortaleza (Pucara), a san Cristobal, a Carmica (Carmenca) e Yllapacancha o templo del Rayo. Llama la atención la figura del rio Watanay. Y del lado derecho está diseñado Uiroypaccha al lado del Curi Cancha o templo del Sol, seguido por Quispi Cancha. Y, cosa curiosa, Guaman Poma introduce en el diseño la torre de la iglesia de san Sebastián al lado de Sancay Uaci o cárcel perpetua.

Claro está, la figura de puma no aparece en el diseño, pero está Pumachupan o Cola de León como barrio, en la parte central inferior del dibujo, como se señala en la tradición oral. Nótese la ubicación del rio Watanay, dividiendo el diseño en dos partes. Si interpreto bien la figura, el agua sigue del otro lado del dibujo, en Quispi cancha. Asi, el espacio global de la ciudad estaría dividido en dos partes, el de arriba y el de abajo, arriba de las aguas, abajo de las aguas. Ahora bien, la leyenda codificada en los cronistas del siglo XVI hablaba de Pumachupan como la parte de la ciudad donde se juntan los dos ríos. No hay traza de esa forma en el diseño de Guaman Poma. Por consiguiente, es razonable pensar que el autor de la Nueva Crónica y Buen Gobierno ignoró la anécdocta de la imagen del puma-ciudad conociendo, sin embargo, el barrio Pumachupan, ubicado entre Cantoc Moya y Belén.

Algunos detalles del dibujo merecen ser comentados. En la parte superior izquierda estan los elementos iconográficos del complejo de la Fortaleza/Cinco Urco-Pucara, Suchona [EI resbaladero] a la cual el autor de la Nueva Crónica y Buen Gobierno no presta mayor atención. Luego sigue san Cristóbal con la Pingollona Pata en el atrio y antes de llegar al rio Huatanay, el barrio de Carmenca. Ubicado en la parte superior derecha, el espacio más importante es el que ocupa el Quri Cancha o Templo del Sol, con una pareja que más se parece a españoles que a indios y una fontana. Digna de ser mencionada es la ventana que probablemente se refiere a la famosa "ventana de Santo Domingo" tal como hoy se ve por encima de la cintura exterior de la iglesia construida en las antiguas ruinas del Templo del Sol (Ver Diseño-2). Esa forma arquitectónica se repite en varios de los dibujos de Guaman Poma, pero sin la abertura de la ventana en la parte superior del diseño. Son los casos de la Audiencia de Quito (Guaman Poma 1980: 922), Puerto Viejo (Guaman Poma 1980: 940), Panamá (Guaman Poma 1980: 946), Lima (Guaman Poma 1980: 950), Santiago (Guaman Poma 1980: 986).

Del diseño de Cuzco de Guaman Poma se pueden sacar algunas lecciones. Las plazas centrales Haucay Pata, Cusi Pata y Cuci Cancha, y la parte inferior con la plaza de Puma chupan, ocupan el espacio central de la ciudad. En la plaza Cusi pata pueden verse las mesas de los indios o personas que vienen vender sus productos, como lo mencionan otros cronistas, entre ellos Martín de Murúa (1590), subrayando la dimensión de mercado que existía ya en tiempos de los incas (Murúa 1946: Libro III, cap. VII). En los diseños de Guaman Poma, las formas 
arquitectónicas de Puma chupan no presentan elementos específicos y no hay señales o símbolos que se refieren al puma o a la Cola del Puma. Por consiguiente, el autor de la Nueva Crónica y Buen Gobierno no juzgó oportuno mencionar rasgos particulares o no los conocía. De esa manera, la figura del puma en la ciudad de Cuzco queda reducida al diseño del barrio Puma chupan.

\section{El mapa del Cuzco de Gaspar de Villagra (1643)}

Existe en el Archivo Arzobispal de Lima el mapa del Cuzco del padre Gaspar de Villagra (1643) donde se diseñan algunos espacios urbanos de la ciudad y se mencionan los dueños de casas o solares, nombres de calles y lugares (Ver Mapa-1). No abarca el documento la totalidad del espacio urbano. Se concentra en algunos barrios, o mejor dicho, parroquias, la de Santa Ana y Carmenga, plaza de san Francisco y el monasterio de santa Clara. También aparecen las calles y casas de la parroquia de Santiago, Belén y del Hospital de los Naturales. Cerca de santa Clara está la carnicería de ganado mayor y menor, y ahi al lado, el Hospital mencionado anteriormente. Para llegar a éste, el mapa señala varias sendas. Hay que cruzar el rio Santiago que trae al barrio lodos pesados y suciedad como bien lo describe el texto que acompaña el dibujo.

Desde el punto de vista estructural, existen dos espacios, el de arriba con la salida a Lima y Santa Ana, y el de abajo dominado por el río Santiago que nos llevaría a Pumachupan, si el mapa se alargara un poco más. El contraste es flagrante. Sin embargo, la parte alta de Carmenga se construyó en torno a la iglesia de Santa Ana, bajando las calles hacia Picchu por un lado, y por el otro lado hacia la calle Nueva. Llegados a tierra plana, se pueden identificar las casas de algunos clérigos: las de Rodrigo Barba, de Juan de Vera, que vino de España, llegó al Cuzco y protagonizó varios escándalos mayúsculos (Urbano 1997: 207-213). Nótese también los distintos propietarios de casas con oficios específicos: plateros, panaderos, tintoreros, arrieros. A la parroquia del Hospital, el mapa dedica varios renglones. Era probablemente una de las razones de su existencia por tratarse de la división de territorios parroquiales.
Sea lo que fuera, lo cierto es que el mapa nos muestra alrededor del Hospital algunas casas más: la de la carnicería, Matará, Belén, la casa de Juan Espinosa y Alonso Días. Importantes edificios son el monasterio de Santa Clara y el convento de san Francisco.

No se mencionan muchos más lugares. De pumas no hay rastro, tampoco lo hay de Pumachupan. Sin embargo, en medio de todo ello hay una visión del espacio urbano que es muy distinta de los registros iconográficos de Guaman Poma. En la pluma de Villagra, Cuzco es una ciudad construida en torno a parroquias, $y$ alrededor de ellas, casas y solares. No hay, por ejemplo, ninguna referencia al mundo indígena ni a construcciones prehispánicas. En ese sentido, se podría afirmar que el mapa de Villagra es la nueva imagen del Cuzco, la de los tiempos virreinales.

\section{La invención del Cuzco-Puma: los viajeros del siglo $\mathrm{XIX}$.}

Una de las grandes paradojas de la anécdota del diseño del Inca Pachacutec y de la figura del puma es la fascinación que la cronística del siglo XVI y XVII ejerció sobre los viajeros del siglo XIX, particularmente sobre uno que resultó ser la fuente de la versión contemporánea de Cuzco, ciudad-puma. El hecho es algo insólito. Sin embargo, es verídico. George Squier, estadounidense, publicó en 1877 la obra en que relataba sus viajes a través de los Andes, llegando a la ciudad del Cuzco y confrontando la cronística que existía publicada en ese entonces con lo que quedaba de la ciudad. Y apoyándose en Garcilaso de la Vega (1609) describe Cuzco prehispánico, dando bastante relieve a la parte incaica. Publica un diseño elaborado por él (Ver plano 2). Y es ese diseño, más que el texto, que impactará en la imaginación de dos reconocidos arqueólogos contemporáneos mencionados anteriormente, uno estadounidense, otro peruano, John Howland Rowe y Manuel Chávez Ballón respectivamente.

\section{Veamos el argumento de Rowe:}

"The area between the rivers was laid out in the shape of a puma, the 
fortress representing the puma's head and the point where the rivers come together representing the tail. This point is still called "The Puma's Tail" in Inca. The space between the puma's front and the back legs constitued a great public square used for ceremonies; it was paved with pebbles. The streets were straight but somewhat irregularly arranged to fit the topography of the site and the puma figure; in consequence, none of the blocks was square, and the blocks varied greatly in size. The streets were narrow, paved with stones, and with a stone-lined water channel running down the middle" (Rowe 1967: 60).

La figura del puma descripta por Rowe es mucho más realista que la de Squier; y si la comparamos con los textos de los cronistas del siglo XVI y XVII es excesiva y inexacta en su aparente realismo. Sacsayhuaman o Fortaleza tiene muy poco, mejor dicho, no tiene nada de la cabeza de un puma, y menos aún posee rasgos del cuerpo del animal, la parte central de la ciudad. Verlo bajo esa figura es tomar los excesos de la imaginación por la traza urbana de la ciudad incaica. Así las cosas, sólo queda la anécdota de la Cola del Puma - Puma Chupan como señal de un diseño que proyectaba en el espacio al cuerpo del animal. Sin embargo, la existencia de la leyenda del Puma Chupan quizá se deba a otras razones y no al dibujo de Pachacutec. Precisamente son aquellas que ignoramos. Queda entonces por explicar su supervivencia y particular vigor en los sesos de los que más deberian dudar de ella.

Rowe no añade mucho a lo que Chávez Ballón afirma. Sin embargo, el diseño que acompaña su texto dibuja la figura del puma. Obvio, es la imagen que viene de Squier. Probablemente, la difusión de esa imagen tuvo su impacto en la tradición académica. Tanto Rowe como Chávez Ballón enseñaron a varias generaciones de arqueólogos y no cabe la menor duda que la figura de Cuzco como puma era uno de sus temas obligatorios. Las guías populares de turismo se sirven de ella para nutrir la imaginación de los visitantes en búsqueda de rarezas y esoterismo.

\section{Las fundaciones del Cuzco}

No repetiré los argumentos eruditos de Barnes y Slive para demostrar que las afirmaciones de Rowe y de Chávez Ballón son una inexacta versión de los dibujos y descripciones del viajero del siglo XIX, Squier. No obstante, hay comprometida en el esfuerzo para rediseñar la ciudad y darle un estatus la expresión metafórica, y sobre todo, la inconfundible función del discurso sin el cual los espacios urbanos no existirían. En otras palabras, los viajeros del siglo XIX y el discurso arqueológico que los asume reinventan la ciudad de Cuzco Puma en un acto de lenguaje que tiene visos de fundación de la ciudad incaica. La afirmación puede parecer extraña. Me abocaré a darle sentido en los próximos párrafos.

Primera fundación de Cuzco: los hermanos Ayar. Hubo una primera fundación de Cuzco que poco o nada tiene que ver con el imagen del puma. Es la que cuentan los relatos míticos de la llegada al valle de Cuzco de los hermanos Ayar, ancestros míticos de los incas. A esta fundación no hacen referencia los textos de Squier ni la pluma equivocada de los arqueólogos Rowe y Chávez Ballón. De los relatos que inauguran el ciclo de la primera fundación de Cuzco, hay algunas imágenes que permanecieron en los desarrollos ulteriores de las descripciones de la ciudad, pero ninguna de ellas lleva el sello de la marca puma. Cuzco, en su primero diseño, es un espacio distribuido entre los cuatro hermanos y hermanas Ayar. $Y$ cada uno de los Ayar desempeña la función que corresponde a la fundación de un espacio social donde son esenciales, las prácticas religiosas, las prácticas agrícolas y las prácticas políticas. Al fundar por la primera vez la ciudad, la palabra mítica encarnada por los Ayar subraya la idea de un espacio construido en base a las funciones religiosas, agrícolas y sociopolíticas. Se podría entonces decir que la palabra mítica transforma el espacio físico del valle de Cuzco en una ciudad, habitada por tres funciones originales: la religiosa (Ayar Uchu), la agrícola (Ayar Auca), la sociopolítica (Ayar Manco) (Urbano 1981)

Segunda fundación de Cuzco: Pachacutec y la guerra de los incas contra los chancas. 
Instalados en el valle del Cuzco, los incas han sido atacados por los chancas. Según los relatos miticos, los chancas llegaron a los alrededores del valle de Cuzco y se volvieron amenazadores hasta en tres ocasiones. De esas guerras sale victorioso Pachacutec, hijo de Viracocha Inca. Asegurada la victoria, Pachacutec pudo dedicarse a otros menesteres y entre ellos a la reconstrucción de Cuzco. De ahi, pues, el diseño de la ciudad y la figura de puma que hemos analizado hasta ahora. Según los relatos de los cronistas que recogieron la anédocta del diseño del puma, el gesto del inca es conforme a la tradición andina que siempre habla de un acto de ordenamiento de las cosas y de la sociedad previamente dibujado por el héroe $o$ dios en una piedra o roca. $Y$ hay elementos arqueológicos que confirman esa manera de ver las cosas (Urbano 1981: LVII-LXI). No lejos del Cuzco, por ejemplo, existe la famosa piedra de Sayhuite que muestra el diseño de un asentamiento humano ordenado. En ese sentido, lo que ha hecho Pachacutec está conforme con las formas y maneras de ser andinas. Sin embargo, una cosa es diseñar la ciudad y otra cosa es darle la figura de puma.

Tercera fundación de Cuzco: la fundación española en 1534. El Acta de fundación de la ciudad española de Cuzco fue publicada y analizada por Porras Barrenechea. Llama el historiador la atención sobre el contenido del texto que incorpora el espacio andino a la Corona española y al designio universal de salvación religiosa del catolicismo. $Y$ muy curiosamente habla de la liberación del pueblo cuzqueño sometido a "extranjeros", es decir a los gobernantes de Quito (Ecuador). Claro está, el documento no habla de la imagen de Cuzco como puma, ni refiere aspectos particulares del diseño de la ciudad. Reconoce, sin embargo, la buena traza de los espacios urbanos, particularmente la de los edificios construidos en piedra, luego aprovechados por los conquistadores y españoles en general (Porras Barrenechea 1961: 77-85).

De las tres fundaciones de la ciudad, se podría retener el principio general de ordenamiento del espacio: en la primera fundación, la de los héroes míticos Ayar, el espacio del valle del Cuzco se define por las funciones que cada uno de los héroes desempeña. Se reducen a tres: la religiosa con la ocupación del cerro Huanacauri por parte de Ayar Uchu; la sociopolítica con la figura de Ayar Mango, que recibe la herencia de los tres otros hermanos; la agrícola con la figura de Ayar Auca. No hablo de Ayar Cachi porque su presencia en el discurso mítico sirve para definir un espacio subterráneo luego del castigo que los otros hermanos deciden de aplicarle. Resumiendo, el espacio de la primera fundación es el que por la primera vez otorga a cada uno de los héroes las características de una sociedad organizada política y religiosamente. De alguna manera es ua acta de fundación como lo será en 1534 la de los conquistadores. Vale la pena compararlas.

Como lo subrayó Porras Barrenechea, los conquistadores señalan dos grandes principios de lectura del espacio cuzqueño: el religioso, recurriendo a la salvación universal del género humano, y el político, asumiendo la liberación de las poblaciones cuzqueñas del yugo quiteño. El texto de la Acta no habla de un espacio agrícola. Sin embargo, recuerda el principio de vida comunitaria propio de la humanidad sin la cual no era posible la sociedad y reproducción humanas. Insiste sobre la liberación de los pueblos indígenas y de su ordenamiento sociopolítico y religioso bajo el poder de la Corona española. Claro está, el Acta no es la expresión de un discurso fundador de un espacio mítico. Aun asi, dibuja un nuevo ordenamiento de Cuzco como expresión del espacio global de la Conquista española. En ese sentido, Cuzco en el Acta se transforma en el diseño de lo que será, de ahí, en adelante todo el espacio bajo el poder español.

Tanto el discurso de la primera fundación como el de la tercera, se alejan de la segunda que atribuimos a Pachacutec. Hay, sin embargo, en la gesta de Pachacutec, la voluntad de redibujar el espacio cuzqueño en términos políticos como más tarde lo hará el conquistador español. Asegurada la victoria sobre los chancas, Pachacutec rediseña el espacio sociopolítico y religioso, dando a la ciudad un paisaje de acuerdo a su importancia en la red de poderes que los incas iban tejendo; el conquistador español, hasta cierto punto, procede de la misma manera, rehaciendo la ciudad, cons- 
truyendo los solares, conventos e iglesias y finalmente, liberando la población indígena del yugo quiteño, sometiéndola a la Corona española.

\section{Sin discurso no hay ciudad o de la fundación de la ciudad por la palabra}

La revisión del caso de Cuzco y de la imagen del puma que la arqueología contemporánea recuperó a través de los viajeros del siglo XIX planteó el problema teórico de la existencia de la "ciudad" como expresión de una forma de vida social o de existencia comunitaria específica que se opone lógicamente a la "comunidad aldeana", más restringida y menos ataviada con servicios y peso colectivo. No hay, por cierto, una definición aceptada universalmente sobre lo que es un espacio urbano. Pero, hay convergencia de puntos de vista, en la medida en que la ciudad fue poco a poco imponiendo su imagen como un espacio abierto y traza ordenada. $Y$ es este aspecto que se confunde en la producción del discurso como acto fundador de la ciudad. Me explico.

Retomando el ciclo mítico de los Ayar como discurso fundador de la ocupación y ordenamiento de Cuzco y de su valle, descubrimos el esfuerzo que hace la palabra o el discurso mítico para definir un espacio y distribuir las funciones según un plan que corresponde sin duda a la visión del mundo y de las cosas difundida por los incas. Según ese principio, el ciclo mítico de los Ayar no es el producto de los Ayar, sino más bien la palabra fundacional del espacio cuzqueño por los incas, que, paulatinamente, fueron elaborando la palabra que ha dado sentido al espacio cuzqueño y lo transformó en espacio sociopolítico y religioso. Por consiguiente, si el espacio urbano cuzqueño existe es porque el ciclo mítico de los Ayar le da la forma y, sobre todo, razón de ser. $Y$ de igual manera ocurre con el Acta de fundación española de la ciudad. Al afirmar que Cuzco, a partir de 1534 , pasa a ser la cabeza de los territorios sudamericanos, el Acta otorga al espacio urbano una nueva función, la de ser la expresión sociopolítica y religiosa de la presencia del conquistador (Porras Barrenechea 1961: 77-86). Nótese: el Acta lo hace con la escritura, el ciclo mítico de los Ayar con la palabra.

\section{Conclusión}

Llegado al término de estas escuetas reflexiones acerca del espacio urbano de Cuzco, tomando como pretexto de ellas el problema planteado por el diseño de la ciudad hecha por el inca Pachacutec en que se decía que él se había inspirado para hacerlo en la imagen del puma, hemos podido concluir que el espacio urbano existe porque la palabra mítica lo hace existir. En el caso del puma, Barnes y Slive demuestraron claramente que se trataba de una metáfora, oriunda de la visión del mundo que los europeos difundieron en el Continente americano. Varias ciudades fundadas por los españoles en América llevaron el nombre de "león", siendo en el Perú la más conocida, León de Huánuco. Con ese nombre recordaba el conquistador sus tierras de origen - las ibéricas - y sugería la fuerza del símbolo puma o león en un nuevo discurso sobre el espacio americano. En ese sentido, la figura del puma no es tanto una figura indígena cuanto un símbolo poderoso de la visión del mundo y de las cosas difundido por los conquistadores (Morales Folguera 2001).

Cada vez más se insiste en la importancia del siglo XIX en la reinvención de espacios basada en lecturas que confunden investigadores, ensayistas y políticos. El discurso indigenista es una de sus víctimas (Rénique 1991). Creyendo restituir al espacio urbano cuzqueño su integridad preshispánica, Squier y los viajeros del siglo XIX acabaron por servir a los arqueólogos y intelectuales desprevenidos un manjar podrido: un discurso ideológico en que subrepticiamente se sugería al lector los nefastos daños del conquistador europeo - obviamente español - y la garantía de libertad que el esplendor prehispánico anunciaba. De esa manera, las crónicas viajeras inventaban sus propias ciudades precolombinas a fin de sacar provecho propio y derivar los beneficios de la presencia europea hacia el poderío de las potencias hegemónicas, Inglaterra y Estados Unidos. No se equivoque el lector: Squier venía de Estados Unidos y no lo guiaban solamente la implacable búsqueda de la "verdad histórica". Tampoco Markham que era inglés y animaba conversatorios en Londres sobre el esplendor de la gesta incaica (Markham 1856). Eran otros sus intereses, fundamentalmente económicos y financieros. Por eso, las metáforas no engañan, excepto a los arqueólogos poco sensibles al uso de la palabra y de la 
escritura. Rowe y Ballón fueron víctimas de su propia ignorancia estilística.

Vengamos a orientaciones más sensatas resumiendo en pocas líneas el argumento.

Las disquisiciones en torno a la figura del puma y del gesto del inca Pachacutec fueron el pretexto para releer los ciclos míticos de fundación de la ciudad. Recordé el de la fundación primera protagonizada por los hermanos Ayar, ancestros míticos de los incas, y luego referí la anédocta de Pachacutec como una segunda fundación. Finalmente busqué en la Acta de la fundación española de la ciudad una expresión diferente, la de la escritura. No obstante, en los dos casos, la palabra mítica y el Acta, desempeñan la misma función: dar forma y figura al espacio urbano porque sin la palabra la ciudad simplemente no existe.

Henrique Urbano

Director del Instituto de Investigación Escuela Profesional de Turismo y Hotelería Universidad de San Martin de Porres ogil@turismo.usmp.edu.pe

\section{Plano 1 Cuzco Incaico}

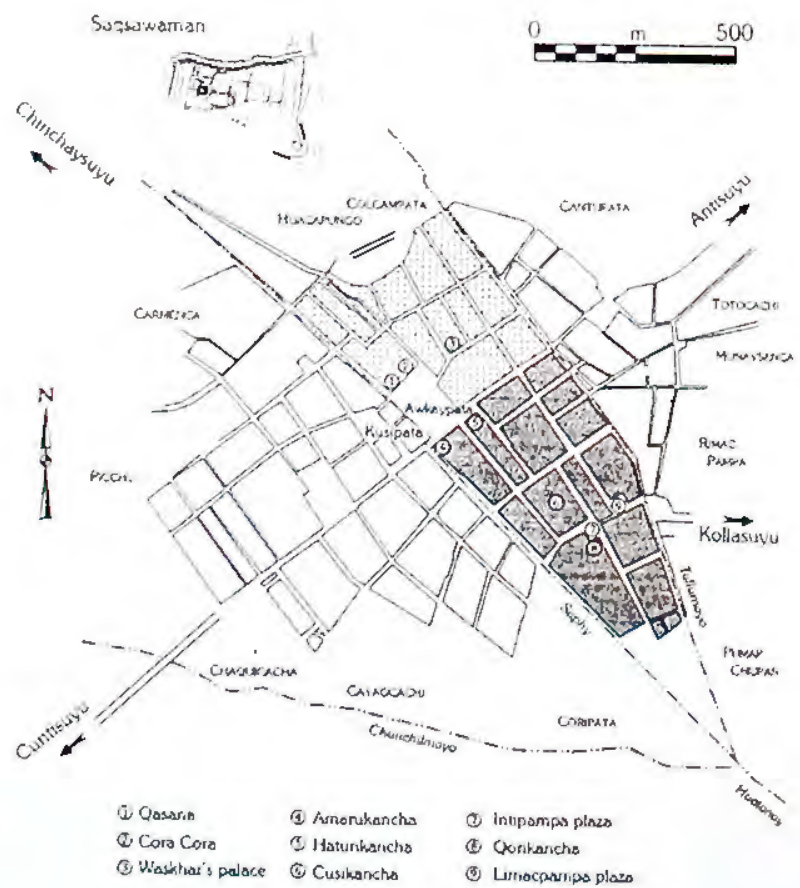

Plano 2

Plano de E.G. Squier 1877

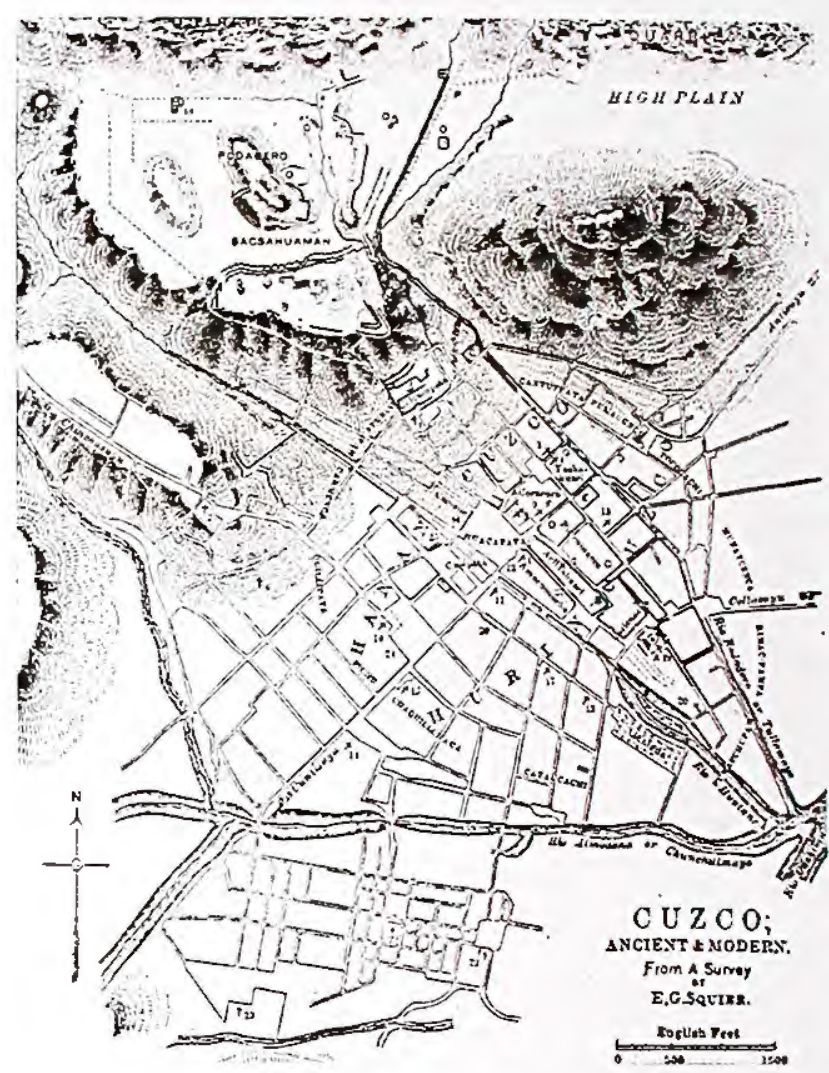

Plano 3

Cuzco Principio del Siglo XX

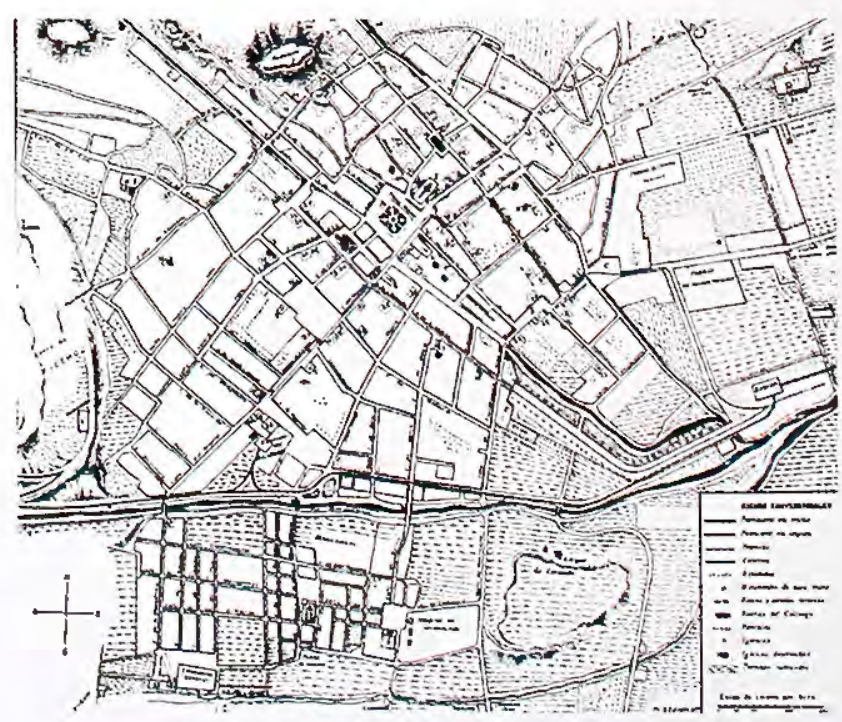




\section{Mapa 1}

Ciudad del Cuzco hecho por el padre Gaspar de Villagra del año 1643

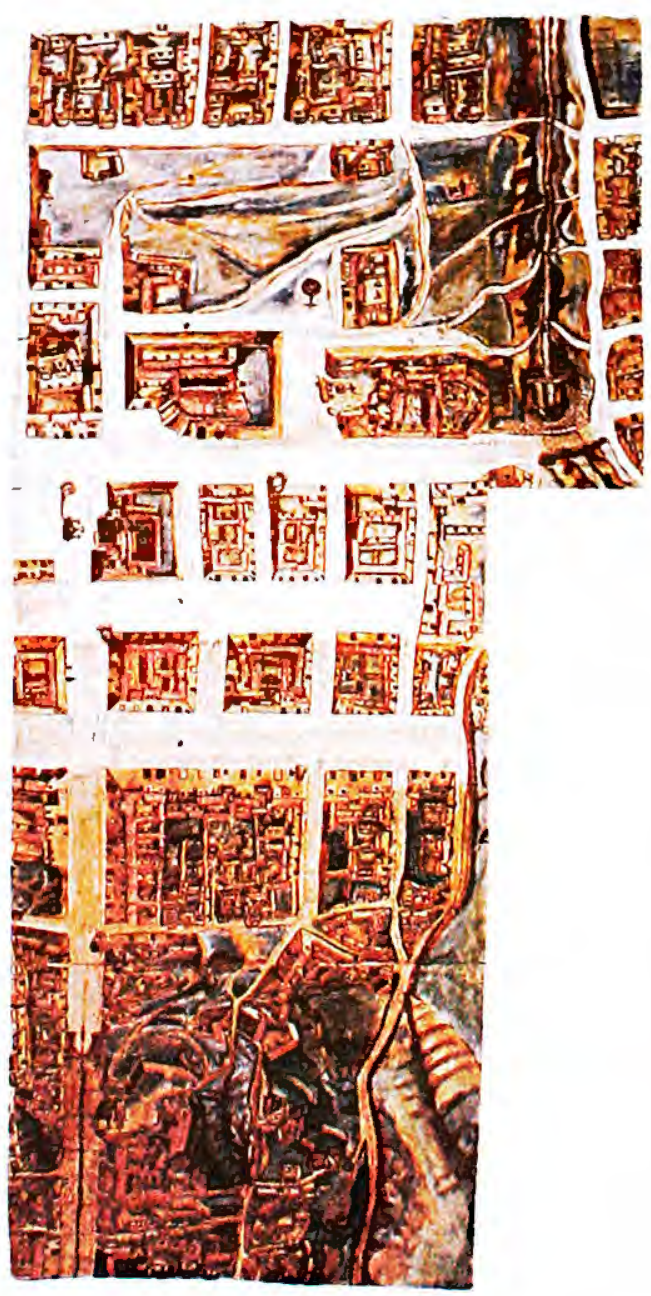

CUZCO-POMAC CHUPAN

(GUAMAN POMA-1613?)

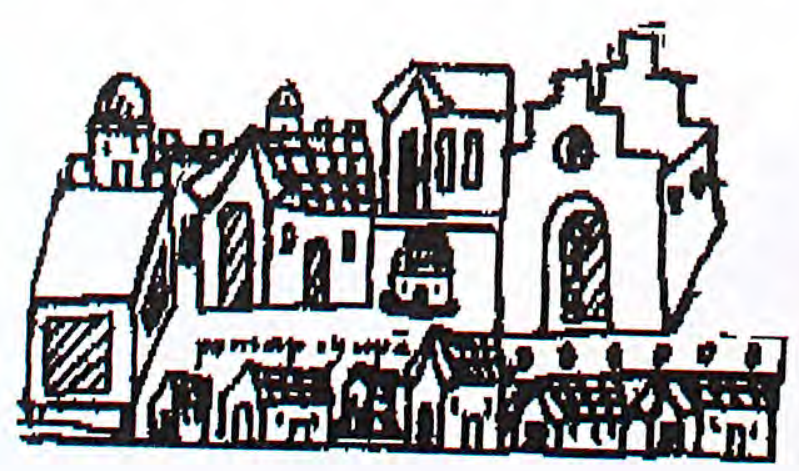

\section{CUZCO-CURI CANCHA [CORI CANCHA] \\ (GUAMAN POMA-1613?)}

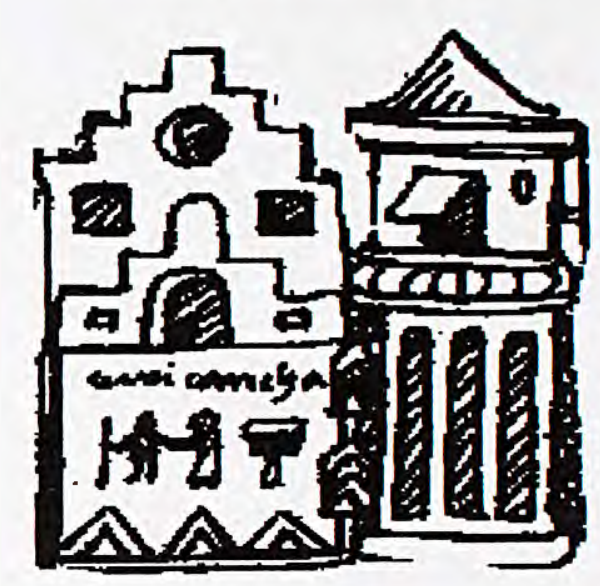

Diseño 2
CUZCO

(GUAMAN POMA-1613?)

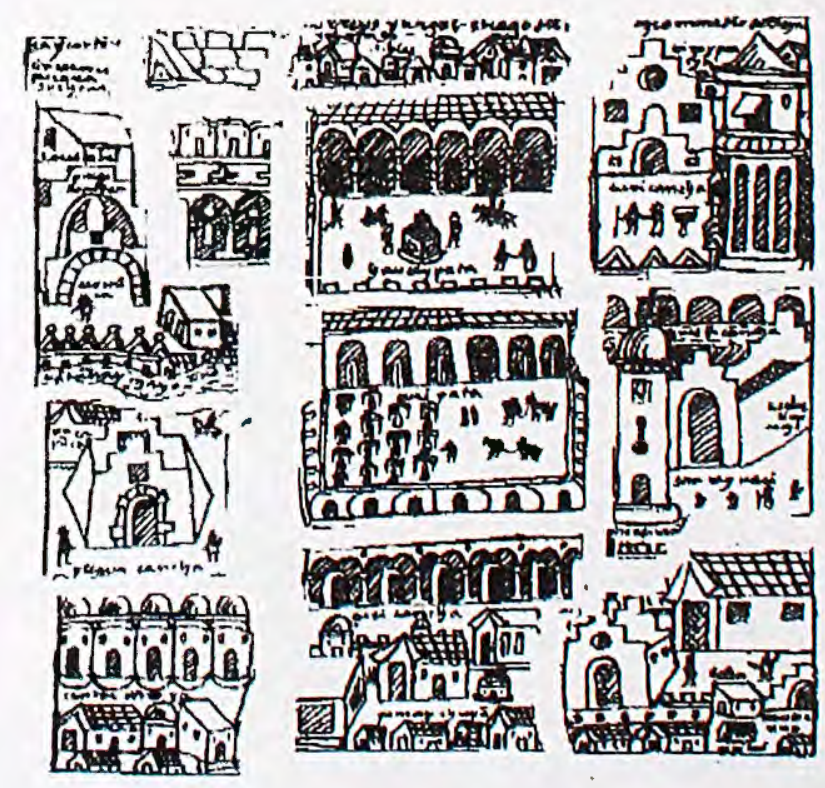

Diseño 3

\section{Diseño 1}




\section{Bibliografía}

BARNES, Mónica y SLIVE, Daniel J.

1993 "El Puma de Cuzco: ¿plano de a ciudad Ynga o noción europea?", Revista Andina, año 11-1 (julio 1993): 79-102.

BETANZOS, Juan

1987 [1551] Suma y narración de los Incas, Atlas, Madrid.

COBO, Bernabé

1964 [1653] Historia del Nuevo Mundo, BAE- XCl-XCll, 2 tomos, Atlas, Madrid.

GARCILASO DE LA VEGA, Inca

1943 [1609] Comentarios reales de los incas, Emecé, Buenos Aires.

GUAMAN POMA DE AYALA, Felipe

1980 [1613?] Nueva crónica y buen gobierno, Siglo XXI, México.

HUSSON, Jean-Philipe

1984 "Les villes péruviennes vues par Felipe Waman Puma de Ayala. Un cas particulier: Cuzco", La ville en Amérique espagnole coloniale, Université de la Sorbonne Nouvelle-Paris III, Paris: 25-49.

MARKHAM, Clemens R.

1856 Cuzco: a Journey to the Ancient Capital of Peru; with an Account of the History, Language, Literature, and Antiquities of the Incas. And Lima: A Visit to the Capital and Provinces of Modern Peru; with a Sketch of the Viceregal Government, History of the Republic, and a Review of the Literature and Society of Peru, Chapman and Hall, London.

MOLINA, EL CUZQUEÑO, Cristóbal

1989 [c.1574] Fábulas y mitos de los incas (Crónicas de América-48), ed. de Henrique Urbano, Historia-16, Madrid.
MORALES FOLGUERA, José Miguel

2001 La construcción de la utopía. El proyecto de Felipe II (1556-1598) para Hispanoamérica, Universidad de Málaga, Málaga.

MURUA, Martin de

1962 [1590] Historia general del Perú (Biblioteca Americana Vetus), ed. Manuel Ballesteros Graibois, Madrid.

PORRAS BARRENECHEA, Raúl

1961 Antología del Cuzco, Librería Internacional del Perú, Lima.

RENIQUE, José Luis

1991 Los sueños de la sierra. Cusco en el siglo $X X$, Cepes, Lima.

ROWE, John $\mathrm{H}$.

1967 "What kind of a settlement was Inca Cuzco?", Nawpa Pacha, 5: 59-76.

SARMIENTO DE GAMBOA, Pedro

1960 [1572] Historia Indica, Publicada en Obras completas del Inca Garcilaso de la Vega, vol. IV (Biblioteca de Autores Españoles135), Atlas, Madrid.

SQUIER, E. George

1974 Un viaje por tierras incaicas. Crónica de una expedición arqueológica (18631865), UNM San Marcos, Lima.

URBANO, Henrique

1981 Wiracocha y Ayar. Héroes y funciones en las sociedades andinas, CBC, Cuzco.

ZUIDEMA, R. Tom

1983 "The Lion in the City: Royal Symbols of Transition in Cusco", Journal of Latin American Lore, vol. 9, n.1: 39-100. 